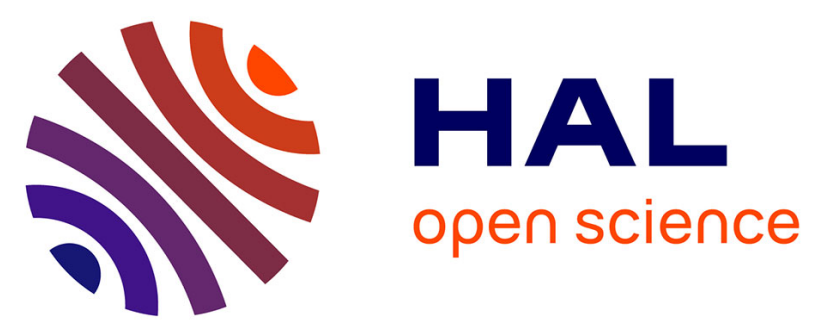

\title{
New-Onset Left Bundle Branch Block After TAVI has a Deleterious Impact on Left Ventricular Systolic Function
} Romain Eschalier, Grégoire Massoullié, Youssef Nahli, Frédéric Jean, Nicolas Combaret, Sylvain Ploux, Géraud Souteyrand, Xavier Chabin, Romain Bosle, Céline Lambert, et al.

\section{To cite this version:}

Romain Eschalier, Grégoire Massoullié, Youssef Nahli, Frédéric Jean, Nicolas Combaret, et al.. NewOnset Left Bundle Branch Block After TAVI has a Deleterious Impact on Left Ventricular Systolic Function. Canadian Journal of Cardiology, 2019, 35, pp.1386 - 1393. 10.1016/j.cjca.2019.05.012 . hal-03488846

\section{HAL Id: hal-03488846 https://hal.science/hal-03488846}

Submitted on 21 Dec 2021

HAL is a multi-disciplinary open access archive for the deposit and dissemination of scientific research documents, whether they are published or not. The documents may come from teaching and research institutions in France or abroad, or from public or private research centers.
L'archive ouverte pluridisciplinaire HAL, est destinée au dépôt et à la diffusion de documents scientifiques de niveau recherche, publiés ou non, émanant des établissements d'enseignement et de recherche français ou étrangers, des laboratoires publics ou privés.

\section{(ㅇ)(1) $\$$}

Distributed under a Creative Commons Attribution - NonCommerciall 4.0 International 


\section{NEW-ONSET LEFT BUNDLE BRANCH BLOCK AFTER TAVI HAS A DELETERIOUS IMPACT ON LEFT}

VENTRICULAR SYSTOLIC FUNCTION.

New-onset LBBB impact on LVEF after TAVI

Romain Eschalier ${ }^{1,4}, \mathrm{MD}, \mathrm{PhD}$; Grégoire Massoullié1, MD ; Youssef Nahli ${ }^{1}$, MD ; Frédéric Jean ${ }^{1}$, MD ; Nicolas Combaret ${ }^{1}$, MD ; Sylvain Ploux ${ }^{3}$, MD, PhD ; Géraud Souteyrand ${ }^{1}$, MD ; Xavier Chabin ${ }^{1}$, MD ; Romain Bosle ${ }^{1}$, MD ; Céline Lambert ${ }^{2}$, MSc; Elodie Chazot $^{1}$; Bernard Citron ${ }^{1}, \mathrm{MD}, \mathrm{PhD}$; Pierre Bordachar ${ }^{3}, \mathrm{MD}, \mathrm{PhD}$; Pascal Motreff ${ }^{1}, \mathrm{MD}, \mathrm{PhD}$; Bruno Pereira $^{2}$, PhD ; Guillaume Clerfond ${ }^{1,4}$, MD.

${ }^{1}$ Cardiology Department, CHU Clermont-Ferrand, Clermont-Ferrand, France and Université Clermont Auvergne, CHU Clermont-Ferrand, CNRS, SIGMA Clermont, Institut Pascal, F-63000 Clermont-Ferrand, France.

${ }_{2}^{2}$ Biostatistics Unit (Clinical Research and Innovation Direction), CHU Clermont-Ferrand, Clermont-Ferrand, France.

${ }^{3}$ Hôpital Cardiologique du Haut-Lévêque, CHU Bordeaux, Université Bordeaux, IHU LIRYC, Bordeaux, France.

${ }^{4}$ INI-CRCT F-CRIN, Nancy, France.

Corresponding AUthor: Romain Eschalier, Cardiology Department, Rue Montalembert, 63000 Clermont-Ferrand, France. Phone: +33473751410; Telecopy.: +33473754730; email: reschalier@chu-clermontferrand.fr

WORD COUNT: 3042 


\section{BRIEF SUMMARY}

We have assessed the impact of new-onset LBBB after TAVI on the left ventricular ejection fraction (LVEF) evolution. Forty consecutive patients were included following the development of new-onset LBBB after TAVI implantation and were matched (age and LVEF) with 40 patients without. A new-onset LBBB was associated with a decrease in LVEF at 8 months, particularly in patients with an initial $\mathrm{LVEF}<50 \%$, thereby potentially affecting their prognosis. 


\section{Abstract}

Background. Transcatheter aortic valve implantation (TAVI) has revolutionized the management of severe aortic stenosis. The development of new-onset complete left bundle branch block (LBBB) is, however, a frequent complication. The objective of the present study was to assess the impact of new-onset LBBB after TAVI on the evolution of left ventricular ejection fraction (LVEF).

Methods. Forty consecutive patients were included following the development of new-onset LBBB after TAVI implantation and were matched for age and LVEF with 40 patients implanted during the same period who did not develop LBBB. The primary endpoint was evolution of the LVEF measured by echocardiography prior to implantation and between 6-12 months after TAVI.

Results. The development of a LBBB was associated with a 5-point decrease in LVEF [-12.5; 2.5], contrary to the non-LBBB group $(1.5[-6.5 ; 9.5], \mathrm{p}=0.007)$ at 8 months, with the persistence of the LBBB $(n=23)$ exacerbating this decrease $(-7[-13 ; 2], p=0.009)$. When left ventricular dysfunction (LVEF $<50 \%$ ) was present prior to TAVI, the appearance of LBBB was associated with a reduction in $\operatorname{LVEF}(-2[-8 ; 2])$ contrary to the non-LBBB group $(20$ [9; 22]), $\mathrm{p}=0.02$.

In Conclusions, the appearance of new-onset LBBB after TAVI has a pejorative impact on left ventricular systolic function, particularly in patients with an initial LVEF $<50 \%$, due to a lack of recovery of the latter, thereby potentially affecting their prognosis.

Key words: TAVI; Heart Valve Prothesis; Left Bundle Branch Block; Ventricular Ejection Fraction, Heart Failure. 


\section{INTRODUCTION}

Calcified aortic stenosis (AS) is the most common of valvulopathies ${ }^{1}$, the incidence of which increases with the increasing life expectancy of the population along with better management of cardiovascular risk factors and heart diseases². Percutaneous transcatheter aortic valve implantation (TAVI) has transformed the management of patients with this disease ${ }^{3}$, particularly those with high and intermediate surgical risk ${ }^{4-6}$.

Numerous advances in implantation techniques and/or in the design of prostheses (anti-leak paravalvular skirt, rigidity of the prostheses, reduction in the size of the introducers) have considerably limited vascular and functional complications ${ }^{7}$. However, atrioventricular conduction complications are highly common and remain a major problem that is both underevaluated and poorly explored. Indeed, the anatomical proximity of the aortic ring and nodo-ventricular conduction pathways favor the occurrence of a left bundle branch block (LBBB) [higher incidence with self-expandable prostheses (30-60\% vs. $6-12 \%)]^{8}$ as well as severe conduction disturbances ${ }^{9}$. The latter are associated with increased post-TAVI morbidity and mortality ${ }^{10,11}$. In the presence of new-onset LBBB, induced electrical asynchrony can lead to ventricular dysfunction or lack of improvement thereof as well as the appearance of high-grade conduction disorders in the long term. The impact of new-onset LBBB after TAVI implantation on left ventricular ejection fraction (LVEF) has never been assessed prospectively. TAVI implantation in patients at intermediate surgical risk and the possible extension of this procedure to low-risk surgical populations under evaluation thus compels cardiologists to anticipate this growing issue.

In light of the above, the objective of the present study was to prospectively assess the impact of the appearance of new-onset LBBB after TAVI on LVEF. 


\section{METHODS}

This is a prospective cohort follow-up study, conducted between June $8^{\text {th }} 2015$ and August $1^{\text {st }}$ 2017 as an ancillary of the LBBB-TAVI study (NCT02482844) ${ }^{12}$. The study was approved by the local ethics committee and the National Health Authority (ANSM: 2015-A00271-48) and the written informed consent of each patient was obtained and archived.

\section{Study Population ${ }^{16}$}

Inclusion criteria were as follows: patients older than 18 years of age; implanted with a TAVI according to the 2012 recommendations of the European Society of Cardiology; expected life expectancy greater than 1 year; sinus rhythm; presence of new-onset complete LBBB post-TAVI persisting for more than 24 hours.

Patients were excluded if they had a pre-TAVI pacemaker or if they had a pre-procedural LBBB or lasting $<24$ hours post-TAVI.

The first 40 patients from the LBBB-TAVI study were included (new-onset LBBB group). During the same inclusion period and within the same center, 40 patients who did not develop an LBBB (non-LBBB TAVI group) were matched to the study population according to age and LVEF $(\geq 50 \%$ or $<50 \%$ ). In both groups, patients were in sinus rhythm and did not require a pacemaker either before or during the follow-up period.

\section{Study Design}

In accordance with the LBBB-TAVI study, included patients underwent an electrophysiological study after TAVI and were implanted, depending on the outcome, with a pacemaker (HV interval $\geq 70 \mathrm{~ms}$ ) or an implantable loop recorder (HV $<70 \mathrm{~ms}$ ). Patients with a pacemaker, eventually only present in the LBBB group, and presenting a ventricular pacing rate greater than $5 \%$ were excluded from this ancillary study. At TAVI post-procedure, patients were divided into two 
groups: patients without LBBB (non-LBBB TAVI group) and those with new-onset LBBB after TAVI (new-onset LBBB group).

A transthoracic echocardiography was performed prior to the TAVI procedure as well as between 6 and 12 months after TAVI.

The primary endpoint was evolution of left ventricular ejection fraction on transthoracic echocardiography (TTE) between pre-TAVI and 6 to 12 months after TAVI. The identification of LBBB was validated by two blinded operators.

\section{Definition of $L B B B$}

Left bundle branch block on the electrocardiogram (ECG) was defined according to the AHA recommendations ${ }^{13}$, namely by a $\mathrm{QRS}$ duration $\geq 120 \mathrm{~ms}$ (in at least one lead); a left delay in V5V6 and aVL leads with a wide, slurred or notched R wave (RR'), and a fast initial ascent; a small R wave in V1-V2, followed by a wide and deep S wave, whose descent is faster than the ascent.

\section{Transthoracic echocardiography}

The echocardiographic study prior to the intervention was performed during the preoperative assessment within a maximum of 1 month before the intervention and within a period of 6 to 12 months after the procedure. TTE was performed using a 2.5 to $5 \mathrm{MHz}$ imaging probe connected to a Vivid 9 ultrasonic device (Vingmed-General Electric, Horten Norway) in accordance with the recommendations of the American Society of Echocardiography and the European Association of Cardiovascular Imaging. Image analysis was subsequently performed by two blinded operators. LVEF was measured from 2D 4-chamber and 2-chamber views (3 loops for each section). The measurement was performed according to Simpson's biplane method described in the recommendations ${ }^{14}$. Aortic regurgitation (AR) was assessed according to recommendations and VARC-II1 criteria 5,16. Aortic regurgitation after TAVI was considered to be significant if at least moderate. 
The change in LVEF was calculated as the difference between the measurement at 6-12 months minus the pre-implantation measurement $\left(\triangle \mathrm{LVEF}=\mathrm{LVEF}_{\text {postTAVI }}-\mathrm{LVEF}_{\text {preTAVI }}\right)$. The variation in LVEF values are presented in LVEF percentage points. One operator's analysis were for the analysis. The second operator's analysis were used to evaluate inter-operator reproducibility. Left ventricle EF was obtained with the best loop acquired. Data were analyzed consecutively in groups of 10 patients.

\section{Sample size and Statistical analysis}

Sample size were calculated according to Cohen's definitons of effect-size bounds as: small (ES: 0.2), medium (ES: 0.5 ) and large (ES: 0.8: grossly perceptible and therefore large), we estimated that 40 patients in each group would be sufficient to detect a $5 \%$ absolute difference in LVEF for an effect size between 0.6 and 0.7 with a two-sided type I error of $5 \%$ and a statistical power greater than $80 \%$. Statistical analyses were performed using Stata software, Version 13 (StataCorp, College Station, TX, US). Tests were two-sided, with a Type I error set at $\alpha=0.05$. Continuous data are expressed as mean \pm standard deviation (SD) or median [interquartile range] according to the statistical distribution (assumption of normality assessed using the Shapiro-Wilk test). Categorical parameters (including ischemic cardiomyopathy, beta-blockers, angiotensin converting enzyme inhibitors, AT1 receptors blockers, procedural access) were compared between groups (new-onset LBBB after TAVI vs. non-LBBB after TAVI) using chisquared or Fisher's exact tests. Quantitative variables (including age, LVEF before TAVI) were compared between groups by Student's t-test or the Mann-Whitney test when the assumptions of the t-test were not met (normality and homoscedasticity analyzed using the Fisher-Snedecor test). A multivariable analysis was next conducted in order to determine whether LVEF after TAVI was significantly different between the two groups, taking an adjustment on) LVEF before TAVI, in addition to other covariates fixed according to the univariable results and clinical relevance: time between TTE and TAVI implantation and presence of beta-blockers. Multiple linear conditional regression models were performed, taking into account matching. Before 
performing a regression model with time between TTE and TAVI implantation and presence of beta-blockers, we ran separate multivariable regression analyses with each parameter. Then, the two variables were added together in multivariable model. Particular attention was paid to possible interaction. The normality of residuals from these models was studied using the Shapiro-Wilk test. When appropriate, a logarithmic transformation was performed to achieve the normality of dependent outcome. Particular attention was given to LVEF before TAVI, which was also considered as a categorical variable classified according to literature as $<50 \%$ or $\geq 50 \%$. Prior to performing subgroup analyses according to LVEF before TAVI, the interaction between groups (new-onset LBBB vs. non LBBB after TAVI) and LVEF before TAVI $(<$ or $\geq 50 \%$ ) was studied. 


\section{RESULTS}

\section{Baseline characteristics (Table 1)}

Overall, 534 patients [326(61\%) with self-expandable valve and 208(39\%) with balloonexpandable valve] underwent a TAVI procedure during the inclusion period. Fifty-one patients (9.6\%, n=51) presented new-onset LBBB after TAVI lasting > 24 hours $(12.3 \%$ new-onset LBBB in patients implanted with self-expandable vs. 5.3\% with balloon-expandable TAVI).

A total of 80 patients were included in the present study. We included the first 40 patients of LBBB-TAVI study. Mean age and proportion of male gender were identical in both groups (82.4 \pm 4.6 vs. $81.5 \pm 5.1$ years, $p=0.40$ and $50 \%$ vs. $60 \%$ in LBBB and non-LBBB groups, respectively; $\mathrm{p}=0.37$ ). There were no differences in terms of pre-TAVI symptoms (NYHA class III or IV) $[12 / 40(30 \%)$ in the LBBB group vs. $16 / 40(40 \%)(\mathrm{p}=0.35)]$. The EUROSCORE also did not differ between the 2 groups (3.8 \pm 2.9 in the LBBB group vs. $3.2 \pm 1.4, \mathrm{p}=0.18$ ). The same was also true for the mean aortic transvalvular gradient in pre-TAVI: $44.2 \pm 15.6 \mathrm{mmHg}$ in the LBBB group vs. $43.4 \pm 14.3 \mathrm{mmHg}(\mathrm{p}=0.83)$. The number of patients implanted with a self-expandable prosthesis was higher in the LBBB group $(82.5 \%$ vs. $47.5 \%, \mathrm{p}=0.001)$.

The rate of moderate or significant aortic regurgitation after TAVI was similar between the 2 groups: $7.5 \%$ in the LBBB group vs. $12.5 \%(\mathrm{p}=0.51)$.

\section{ECG characteristics}

Among the patients with new-onset LBBB, 97.5\% still exhibited a LBBB at hospital discharge (between D5 and D7), with 58\% at TTE follow-up assessment. The mean QRS duration of the LBBB at hospital discharge was $151 \pm 17 \mathrm{~ms}$ vs. $102 \pm 14 \mathrm{~ms}$ in the non-LBBB group ( $\mathrm{p}<0.001)$. Patients who did not present a complete LBBB after TAVI had the following ECG features: 1 patient had a left anterior fascicular block, 3 had an incomplete LBBB $<120 \mathrm{~ms}$, 2 had a nonspecific intraventricular conduction delay and 3 had a right bundle branch block $\geq 120 \mathrm{~ms}$. A total of 34 patients had a narrow QRS $<120 \mathrm{~ms}$. 


\section{Evolution of left ventricular ejection fraction (Table 2)}

LVEF evaluation was performed within a mean delay of $8.1 \pm 4.1$ months after TAVI in the LBBB group vs. $8.3 \pm 5.5$ months in the non-LBBB group $(\mathrm{p}=0.91)$.

A decrease in LVEF of 5 percentage points $[-12.5 ; 2.5]$ was observed in instances of new-onset LBBB in contrast to the non-LBBB group which featured an increase of 1.5 percentage points [6.5; 9.5], $\mathrm{p}=0.007$. Among patients with pre-TAVI left ventricular dysfunction (LVEF $<50 \%$ ), the appearance of LBBB was associated with a decrease in LVEF of -2[-8 - 2] as opposed to patients without LBBB who had an increase in LVEF of 20[9;22], ( $p=0.02)$ (Figure 1).

During follow-up, LVEF of patients with persistent LBBB was reduced by -7 points $[-13 ; 2]$ $(n=23)$, comparatively to patients who recovered from LBBB $(-2$ points $[-7 ; 6](n=17))$ and those without new-onset LBBB after TAVI $(1.5[-6.5 ; 9.5], \mathrm{n}=40, \mathrm{p}=0.009)$, with a regression coefficient of 10.76 [6.01; 15.52] adjusted to pre-TAVI LVEF, QRS duration, valve type and the presence of beta-blockers between persistent LBBB and non LBBB patients (taking into account LBBB and non-LBBB groups matching).

\section{Morbidity and mortality}

During the 12-month follow-up, there were no differences in hospitalizations for HF in the newonset LBBB post-TAVI vs. the non-LBBB groups $[2 / 40$ patients $(5 \%)$ in the new-onset LBBB group vs. $3 / 40$ patients $(7.5 \%), p=0.65]$, as well as no difference in mortality rate $[1 / 40$ patients (3\%) vs. $4 / 40$ patients (10\%), $\mathrm{p}=0.36]$.

\section{Discussion}

This study is the first to prospectively follow the outcome of patients developing new-onset LBBB persisting for more than 24 hours after TAVI (both self-expandable and balloonexpandable valves) as well as its long-term consequences on left ventricular systolic function. The appearance of a post-TAVI LBBB was associated with a degradation in LVEF limiting the 
expected benefits of the intervention. The reduction in LVEF was even more pronounced when LBBB persisted beyond 6 months and in those patients with left ventricular dysfunction (LVEF $<50 \%$ ) prior to TAVI implantation.

The low incidence of conduction disorders (9.6\%) and the observed higher prevalence of selfexpanding prostheses $(82.5 \%)$ are comparable to the most recent data in the literature and the reference studies ${ }^{17}$. Although the prevalence of conduction abnormalities varies depending on the studies and type of valve (from 10.5\% [PARTNER registry, Edwards ${ }^{\circledR}$ valve] to 37\% [France 2 registry, Corevalve Medtronic ${ }^{\circledR}$ self-expanding valves]), such prevalence has tended to decrease with operator experience but also the use of the more recent prostheses (Medtronic Corevalve Evolut R and Edwards Sapiens XT valves). ${ }^{18}$ The onset of these abnormalities can be delayed and transient (50\% persistence at 6 months) ${ }^{19}$. Similarly, due to its more aggressive conformation in the aortic outflow track, the self-expanding valve is likely to generate more conduction abnormalities without compromising long-term prognosis.

In instances of left ventricular dysfunction, replacement of the aortic valve for severe aortic stenosis is associated with an improvement in LVEF. Whether using the percutaneous or surgical approach, LVEF recovery, including in high-risk patients, evolves towards a near normalization of the parameters depending on the degree of contractile reserve, including in the long term [TVT registry: from $35.7 \pm 8.5 \%$ to $48.6 \pm 11.3 \%(\mathrm{p}<0.0001) 1$ year after TAVI and similarly from $38.0 \pm 8.0 \%$ to $50.1 \pm 10.8 \%$ ( $\mathrm{p}<0.001$ ) after surgery]. Indeed, left ventricular dysfunction is progressive and often the consequence of an elevation in afterload. Elimination of the outflow obstruction explains the improvement in LVEF in patients undergoing early aortic valve replacement. More generally, an improvement in LVEF or an absence of impairment is also expected when there is no pre-existing left ventricular dysfunction ${ }^{20}$.

In the present study, a LBBB after TAVI hindered this recovery. It counterbalanced the improvement expected by the reduction in afterload when LVEF was normal and above all, it did 
not allow observing an improvement in LVEF in cases of left ventricular dysfunction. One explanation lies in the electro-mechanical effect of LBBB on left ventricular activation characteristics ${ }^{21,22}$. Electrical activation of the right ventricle by the nodo-Hisian pathways is preserved. On the other hand, both interventricular and intraventricular dyssynchrony (late activation of the left lateral wall) alters the quality of the cardiac contraction ${ }^{21}$. In the long term, it is responsible for reverse left ventricular remodeling with a reduction in LVEF and, in certain cases, heart failure ${ }^{10}$.

All of the studies specifically related to the impact of LBBB have reported the degradation or, at the very least, the absence of improvement of LVEF in instances of new-onset LBBB (LVEF at 6 months, narrow QRS 58.1\% vs. LBBB 52.8\%, p<0.001 PARTNER Study; LVEF at 6 months, narrow post-procedure QRS $+4.6 \pm 7.8$ vs. LBBB-T $-2.1 \pm 6.9 \%, \mathrm{p}=0.002$, Dobson et al.23, and $7.39 \pm 9.05 \%$ vs. $-0.46 \pm 5.63 \%, \mathrm{p}<0.001$, Carraba et al. ${ }^{24}$ ). However, these studies, while akin to LBBB-TAVI, mainly focused on either one type of prosthesis (balloon-expandable ${ }^{24}$ or selfexpandable ${ }^{25}$ ) or without a matching of their population ${ }^{23}$. Moreover, these studies were the result of retrospective data and in many instances performed prior to the advent of lastgeneration valves (in contrast to the Evolut R and Sapiens XT valves included in the present study) and whose hemodynamic and structural characteristics tended to modify their behavior in vivo ${ }^{19,2627}$. In addition, there are very sparse data on the long-term evolution of LVEF19,24,26,27. In the long term, the impact of the reduction in LVEF and of a new-onset LBBB on morbidity and mortality remains nevertheless controversial26,28-31. The hemodynamic repercussions of LBBB may be less well tolerated by the remodeled and hypertrophied left ventricle of a patient who is often elderly and with a prior history of aortic stenosis.

These considerations are essential, given that patients with severe aortic stenosis with left ventricular dysfunction account for approximately $10 \%$ of the population with aortic stenosis 32 (17.5\% in the present study) and the reduction in post-TAVI LVEF appears to be associated with a higher mortality and hospitalization rate in those patients with more severe heart failure ${ }^{33,34}$. 
Further studies enabling to stratify the management of these patients exhibiting new-onset LBBB is necessary with regard to the rhythmic and hemodynamic outcome of these patients. Indeed, while the LBBB disappears in nearly half of affected patients, there are currently no predictive elements with regard to the persistence of new-onset LBBB after TAVI. Its persistence may ultimately warrant prevention of LVEF dysfunction appearance by bi-ventricular pacing in these patients presenting new-onset LBBB and a left ventricular dysfunction even of moderate grade (e.g. LVEF < 50\%). On the other hand, adaptation of the type of valve to be implanted in patients with left ventricular dysfunction could represent an appealing avenue given the notable differences highlighted between self-expandable and balloon-expandable valves ${ }^{8}$. This point is of particular importance in that the newer valves being developed are seemingly more conducive to conductive disorders, albeit with a near zero rate of aortic regurgitation 35,36 .

The study has some limitations, mainly the observational design and small sample size. However, the groups were matched on age and LEVF and the sample size seems relevant to meet the primary objective. Due to the relative small population, only large effects could be highlighted, notably to study the secondary objectives and the sub-groups analyses. Residual confounding remains a possibility and there remains a risk of bias, despite the conservative regression analysis. The present study remains the first study conducted prospectively in this frequent population and whose outcome remains uncertain. It moreover represents one of largest cohorts established to date and will help to gain a greater understanding of the underlying mechanisms at play in these patients with new-onset LBBB. Other parameters assessing systolic function such as the Tei index, the measurement of the S' velocity of the mitral annulus at the septal and lateral levels, or as recently described, the study of myocardial deformation or speckle tracking could be more effective and will need to be evaluated ${ }^{37}$. Notwithstanding the latter, LVEF remains the indispensable measurement parameter currently used $^{38}$ in cardiology for the assessment, management and stratification of patient risk, and remains a strong and reproducible marker of left ventricular systolic function. None of the 
patients in our study were screened for the presence of a contractile reserve (stress echocardiography, MRI). The worsening or lack of improvement of LVEF could be attributable to a reduction in contraction reserve. However, the opposite evolution of LVEF at 6 months in patients without LBBB or who had recovered from LBBB would suggest a minor impact of this particular parameter. 


\section{CONCLUSION}

The development of new-onset LBBB after TAVI, particularly when persisting beyond 6 months, has a pejorative impact on left ventricular systolic function, especially in patients with an initial LVEF $<50 \%$. Complementary studies aimed at decreasing the rate of new-onset LBBB after TAVI procedure but also to guide the management strategy of such patients are necessary. 
Acknowledgements: We thank Mr. Pierre Pothier and Mr Pelle Stolt for the editing of this manuscript. 
DECLARATION OF INTERESTS : None. 


\section{REFERENCES}

1. Ross J, Braunwald E. Aortic stenosis. Circulation. 1968;38(1 Suppl):61-67.

2. Turina J, Hess 0, Sepulcri F, Krayenbuehl HP. Spontaneous course of aortic valve disease. Eur Heart J. 1987;8(5):471-483.

3. Cribier A, Eltchaninoff $\mathrm{H}$, Bash A, et al. Percutaneous transcatheter implantation of an aortic valve prosthesis for calcific aortic stenosis: first human case description. Circulation. 2002;106(24):3006-3008.

4. Vahanian A, Alfieri O, Andreotti F, et al. Guidelines on the management of valvular heart disease (version 2012): the Joint Task Force on the Management of Valvular Heart Disease of the European Society of Cardiology (ESC) and the European Association for Cardio-Thoracic Surgery (EACTS). Eur J Cardio-Thorac Surg Off J Eur Assoc Cardio-Thorac Surg. 2012;42(4):S1-44. doi:10.1093/ejcts/ezs455

5. Holmes DR, Mack MJ, Kaul S, et al. 2012 ACCF/AATS/SCAI/STS expert consensus document on transcatheter aortic valve replacement. J Am Coll Cardiol. 2012;59(13):1200-1254. doi:10.1016/j.jacc.2012.01.001

6. Nishimura RA, Otto CM, Bonow RO, et al. 2014 AHA/ACC guideline for the management of patients with valvular heart disease: executive summary: a report of the American College of Cardiology/American Heart Association Task Force on Practice Guidelines. J Am Coll Cardiol. 2014;63(22):2438-2488. doi:10.1016/j.jacc.2014.02.537

7. Kodali S, Pibarot P, Douglas PS, et al. Paravalvular regurgitation after transcatheter aortic valve replacement with the Edwards sapien valve in the PARTNER trial: characterizing patients and impact on outcomes. Eur Heart J. 2015;36(7):449-456. doi:10.1093/eurheartj/ehu384

8. Erkapic D, De Rosa S, Kelava A, Lehmann R, Fichtlscherer S, Hohnloser SH. Risk for permanent pacemaker after transcatheter aortic valve implantation: a comprehensive analysis of the literature. J Cardiovasc Electrophysiol. 2012;23(4):391-397. doi:10.1111/j.15408167.2011.02211.x

9. Marzahn C, Koban C, Seifert M, et al. Conduction recovery and avoidance of permanent pacing after transcatheter aortic valve implantation. J Cardiol. 2018;71(1):101-108. doi:10.1016/j.jjcc.2017.06.007

10. Zannad F, Huvelle E, Dickstein $\mathrm{K}$, et al. Left bundle branch block as a risk factor for progression to heart failure. Eur J Heart Fail. 2007;9(1):7-14. doi:10.1016/j.ejheart.2006.04.011

11. El-Khally Z, Thibault B, Staniloae C, et al. Prognostic significance of newly acquired bundle branch block after aortic valve replacement. Am J Cardiol. 2004;94(8):1008-1011. doi:10.1016/j.amjcard.2004.06.055

12. Massoullié G, Bordachar P, Irles D, et al. Prognosis assessment of persistent left bundle branch block after TAVI by an electrophysiological and remote monitoring risk-adapted algorithm: rationale and design of the multicentre LBBB-TAVI Study. BMJ Open. 2016;6(10):e010485. doi:10.1136/bmjopen-2015-010485

13. Surawicz B, Childers R, Deal BJ, et al. AHA/ACCF/HRS recommendations for the standardization and interpretation of the electrocardiogram: part III: intraventricular conduction disturbances: a scientific statement from the American Heart Association 
Electrocardiography and Arrhythmias Committee, Council on Clinical Cardiology; the American College of Cardiology Foundation; and the Heart Rhythm Society. Endorsed by the International Society for Computerized Electrocardiology. J Am Coll Cardiol. 2009;53(11):976-981. doi:10.1016/j.jacc.2008.12.013

14. Lang RM, Badano LP, Mor-Avi V, et al. Recommendations for Cardiac Chamber Quantification by Echocardiography in Adults: An Update from the American Society of Echocardiography and the European Association of Cardiovascular Imaging. Eur Heart J Cardiovasc Imaging. 2015;16(3):233-271. doi:10.1093/ehjci/jev014

15. Abdelghani M, Tateishi H, Spitzer E, et al. Echocardiographic and angiographic assessment of paravalvular regurgitation after TAVI: optimizing inter-technique reproducibility. Eur Heart J Cardiovasc Imaging. 2016;17(8):852-860. doi:10.1093/ehjci/jew083

16. Kappetein AP, Head SJ, Généreux P, et al. Updated standardized endpoint definitions for transcatheter aortic valve implantation: the Valve Academic Research Consortium-2 consensus document (VARC-2). Eur J Cardio-Thorac Surg Off J Eur Assoc Cardio-Thorac Surg. 2012;42(5):S45-60. doi:10.1093/ejcts/ezs533

17. Massoullié G, Bordachar P, Ellenbogen KA, et al. New-Onset Left Bundle Branch Block Induced by Transcutaneous Aortic Valve Implantation. Am J Cardiol. 2016;117(5):867-873. doi:10.1016/j.amjcard.2015.12.009

18. Nuis R-J, van Mieghem NM, van der Boon RM, et al. Effect of experience on results of transcatheter aortic valve implantation using a Medtronic CoreValve System. Am J Cardiol. 2011;107(12):1824-1829. doi:10.1016/j.amjcard.2011.02.315

19. Houthuizen $\mathrm{P}$, van der Boon RMA, Urena $\mathrm{M}$, et al. Occurrence, fate and consequences of ventricular conduction abnormalities after transcatheter aortic valve implantation. EuroIntervention J Eur Collab Work Group Interv Cardiol Eur Soc Cardiol. 2014;9(10):11421150. doi:10.4244/EIJV9I10A194

20. Poulin F, Carasso S, Horlick EM, et al. Recovery of left ventricular mechanics after transcatheter aortic valve implantation: effects of baseline ventricular function and postprocedural aortic regurgitation. J Am Soc Echocardiogr Off Publ Am Soc Echocardiogr. 2014;27(11):1133-1142. doi:10.1016/j.echo.2014.07.001

21. Eschalier R, Ploux S, Lumens J, et al. Detailed analysis of ventricular activation sequences during right ventricular apical pacing and left bundle branch block and the potential implications for cardiac resynchronization therapy. Heart Rhythm. 2015;12(1):137-143. doi:10.1016/j.hrthm.2014.09.059

22. Vernooy K, Verbeek XAAM, Peschar M, et al. Left bundle branch block induces ventricular remodelling and functional septal hypoperfusion. Eur Heart J. 2005;26(1):91-98. doi:10.1093/eurheartj/ehi008

23. Dobson LE, Musa TA, Uddin A, et al. The impact of trans-catheter aortic valve replacement induced left-bundle branch block on cardiac reverse remodeling. J Cardiovasc Magn Reson Off J Soc Cardiovasc Magn Reson. 2017;19(1):22. doi:10.1186/s12968-017-0335-9

24. Carrabba N, Valenti R, Migliorini A, et al. Impact on Left Ventricular Function and Remodeling and on 1-Year Outcome in Patients With Left Bundle Branch Block After Transcatheter Aortic Valve Implantation. Am J Cardiol. 2015;116(1):125-131. doi:10.1016/j.amjcard.2015.03.054 
25. Tzikas A, van Dalen BM, Van Mieghem NM, et al. Frequency of conduction abnormalities after transcatheter aortic valve implantation with the Medtronic-CoreValve and the effect on left ventricular ejection fraction. Am J Cardiol. 2011;107(2):285-289. doi:10.1016/j.amjcard.2010.09.015

26. Urena M, Webb JG, Cheema A, et al. Impact of new-onset persistent left bundle branch block on late clinical outcomes in patients undergoing transcatheter aortic valve implantation with a balloon-expandable valve. JACC Cardiovasc Interv. 2014;7(2):128-136. doi:10.1016/j.jcin.2013.08.015

27. Nazif TM, Williams MR, Hahn RT, et al. Clinical implications of new-onset left bundle branch block after transcatheter aortic valve replacement: analysis of the PARTNER experience. Eur Heart J. 2014;35(24):1599-1607. doi:10.1093/eurheartj/eht376

28. Houthuizen P, Van Garsse LAFM, Poels TT, et al. Left bundle-branch block induced by transcatheter aortic valve implantation increases risk of death. Circulation. 2012;126(6):720728. doi:10.1161/CIRCULATIONAHA.112.101055

29. López-Aguilera J, Segura Saint-Gerons JM, Mazuelos Bellido F, et al. Effect of New-Onset Left Bundle Branch Block After Transcatheter Aortic Valve Implantation (CoreValve) on Mortality, Frequency of Re-Hospitalization, and Need for Pacemaker. Am J Cardiol. 2016;118(9):13801385. doi:10.1016/j.amjcard.2016.07.057

30. Testa L, Latib A, De Marco F, et al. Clinical impact of persistent left bundle-branch block after transcatheter aortic valve implantation with CoreValve Revalving System. Circulation. 2013;127(12):1300-1307. doi:10.1161/CIRCULATIONAHA.112.001099

31. Schymik G, Tzamalis P, Bramlage P, et al. Clinical impact of a new left bundle branch block following TAVI implantation: 1-year results of the TAVIK cohort. Clin Res Cardiol Off J Ger Card Soc. 2015;104(4):351-362. doi:10.1007/s00392-014-0791-2

32. Kerckhoffs RCP, Faris OP, Bovendeerd PHM, et al. Electromechanics of paced left ventricle simulated by straightforward mathematical model: comparison with experiments. Am J Physiol Heart Circ Physiol. 2005;289(5):H1889-1897. doi:10.1152/ajpheart.00340.2005

33. Baron SJ, Arnold SV, Herrmann HC, et al. Impact of Ejection Fraction and Aortic Valve Gradient on Outcomes of Transcatheter Aortic Valve Replacement. J Am Coll Cardiol. 2016;67(20):2349-2358. doi:10.1016/j.jacc.2016.03.514

34. Sato K, Kumar A, Jones BM, et al. Reversibility of Cardiac Function Predicts Outcome After Transcatheter Aortic Valve Replacement in Patients With Severe Aortic Stenosis. J Am Heart Assoc. 2017;6(7). doi:10.1161/JAHA.117.005798

35. Eksik A, Yildirim A, Gul M, et al. Comparison of Edwards Sapien XT versus Lotus Valve Devices in Terms of Electrophysiological Study Parameters in Patients Undergoing TAVI. Pacing Clin Electrophysiol PACE. 2016;39(10):1132-1140. doi:10.1111/pace.12917

36. Meredith IT, Walters DL, Dumonteil N, et al. 1-Year Outcomes With the Fully Repositionable and Retrievable Lotus Transcatheter Aortic Replacement Valve in 120 High-Risk Surgical Patients With Severe Aortic Stenosis: Results of the REPRISE II Study. JACC Cardiovasc Interv. 2016;9(4):376-384. doi:10.1016/j.jcin.2015.10.024

37. Yotti R, Bermejo J, Benito Y, et al. Validation of noninvasive indices of global systolic function in patients with normal and abnormal loading conditions: a simultaneous 
echocardiography pressure-volume catheterization study. Circ Cardiovasc Imaging. 2014;7(1):164-172. doi:10.1161/CIRCIMAGING.113.000722

38. Schiller NB, Shah PM, Crawford M, et al. Recommendations for quantitation of the left ventricle by two-dimensional echocardiography. American Society of Echocardiography Committee on Standards, Subcommittee on Quantitation of Two-Dimensional Echocardiograms. J Am Soc Echocardiogr Off Publ Am Soc Echocardiogr. 1989;2(5):358-367. 


\section{TABLE AND FIGURES}

Table 1. Clinical characteristics according to the presence or absence of post-TAVI LBBB. ACE: Angiotensin converting enzyme; AR: Aortic regurgitation; CABG: coronary artery bypass graft; LBBB: left bundle branch block; NYHA: New York Heart Association; MDRD: Modification of diet in renal disease; TAVI: Transcatheter aortic valve implantation. 
Table 2. Left ventricular ejection fraction evolution after Transcatheter aortic valve implantation according to left bundle branch block appearance and persistence. LBBB=left bundle branch block; LVEF=Left ventricular ejection fraction, TTE=Transthoracic echocardiography. 
Figure. Evolution of left ventricular ejection fraction during follow-up in the presence or absence of post-Transcatheter Aortic Valve Implantation left bundle branch block. LBBB: left bundle branch block; LVEF: Left ventricular ejection fraction, TTE: Transthoracic echocardiography. 


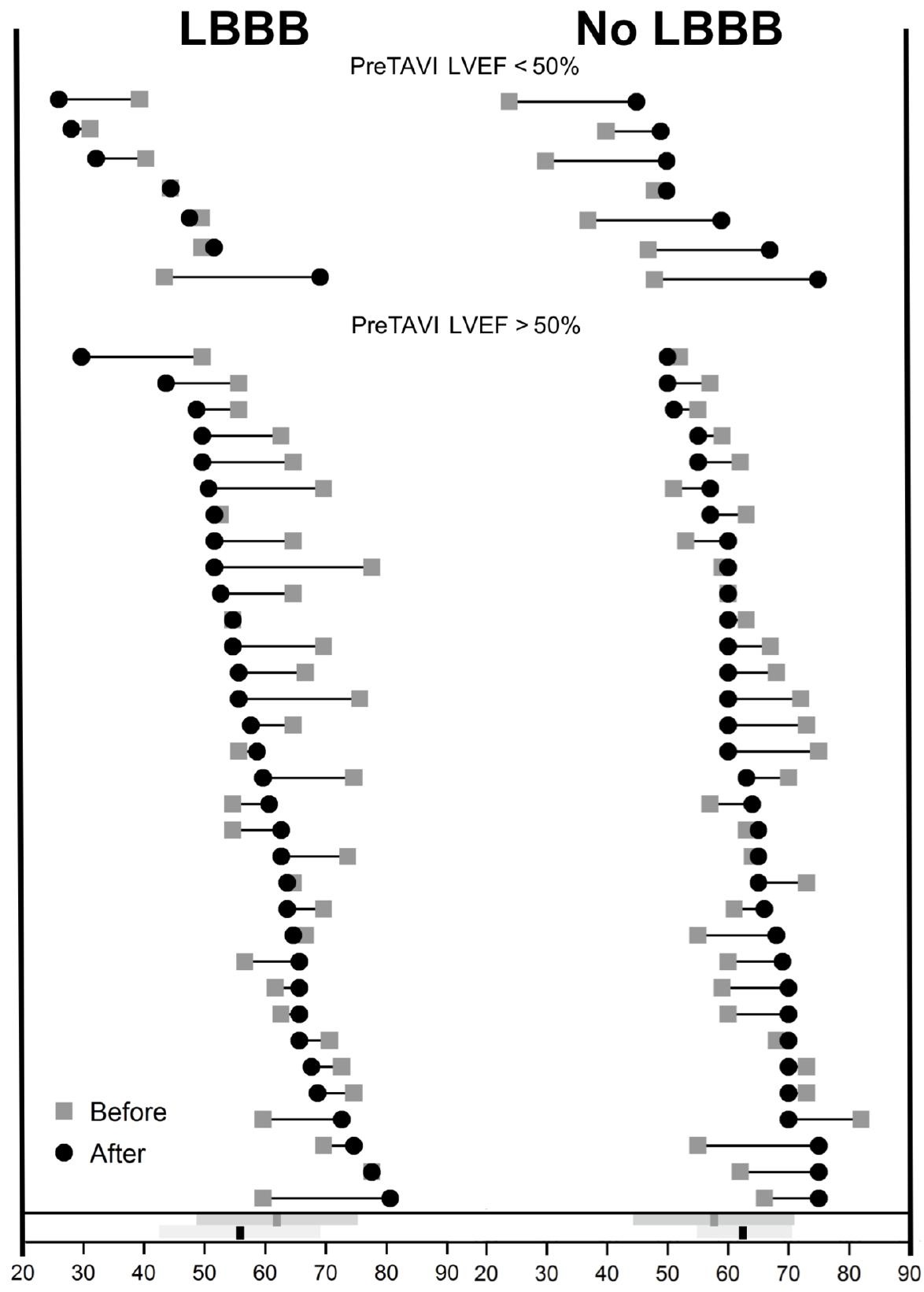




\begin{tabular}{|c|c|c|c|c|}
\hline & $\begin{array}{l}\text { TOTAL } \\
(n=80)\end{array}$ & $\begin{array}{r}\text { LBBB } \\
(n=40)\end{array}$ & $\begin{array}{r}\text { Non-LBBB } \\
(n=40)\end{array}$ & p-value \\
\hline \multicolumn{5}{|l|}{ Clinical characteristics } \\
\hline Age, years & $82.0 \pm 4.9$ & $82,4 \pm 4,6$ & $81.5 \pm 5.1$ & 0.40 \\
\hline Male gender, $\mathrm{n}(\%)$ & $46(57.5)$ & $21(52.5)$ & $25(62.5)$ & 0.37 \\
\hline NYHA (III or IV) & $28(35.0)$ & $12(30.0)$ & $16(40.0)$ & 0.35 \\
\hline EuroSCORE II & $3.5 \pm 2.3$ & $3.8 \pm 2.9$ & $3.2 \pm 1.4$ & 0.18 \\
\hline EuroSCORE Logistic & $12.8 \pm 7.7$ & $12.8 \pm 8.7$ & $12.8 \pm 6.7$ & 0.99 \\
\hline Prior CABG, n(\%) & $40(50.0)$ & $3(7.5)$ & $3(7.5)$ & 0.99 \\
\hline Hypertension, n(\%) & $65(81.2)$ & $37(92.5)$ & $28(70.0)$ & 0.01 \\
\hline Diabetes mellitus, n(\%) & $25(36.3)$ & $13(67.5)$ & $12(30.0)$ & 0.81 \\
\hline Mean aortic valve gradient, $\mathrm{mmHg}$ & $43.8 \pm 14.9$ & $44.2 \pm 15.6$ & $43.4 \pm 14.3$ & 0.83 \\
\hline Chronic respiratory insufficiency, n(\%) & $12(15.0)$ & $6(15.0)$ & $6(15.0)$ & 1.00 \\
\hline Renal insufficiency (MDRD clearance $<30 \mathrm{~mL} / \mathrm{min}$ ) & $4(5.0)$ & $3(7.5)$ & $1(2.5)$ & 0,62 \\
\hline Ischemic heart disease, $\mathrm{n}(\%)$ & $44(55.0)$ & $24(60.0)$ & $20(50.0)$ & 0.37 \\
\hline Beta-blockers, n(\%) & $24(30.0)$ & $14(35.0)$ & $10(25.0)$ & 0.33 \\
\hline ACE inhibitors, $\mathrm{n}(\%)$ & $34(42.5)$ & $19(47.5)$ & $15(37.5)$ & 0.37 \\
\hline \multicolumn{5}{|l|}{ Procedure-related characteristics } \\
\hline Medtronic Corevalve or Corevalve Evolut- $\mathrm{R}$ & $52(65.0)$ & $33(82.5)$ & $19(47.5)$ & 0.001 \\
\hline \multicolumn{5}{|l|}{ (vs. Edwards Sapien, Sapien XT or Sapien 3) } \\
\hline \multicolumn{5}{|l|}{ Diameter } \\
\hline $23 \mathrm{~mm}$ & $15(18.7)$ & $6(15.0)$ & $9(22.5)$ & 0.02 \\
\hline $26 \mathrm{~mm}$ & $30(37.5)$ & $12(30.0)$ & $18(45.0)$ & \\
\hline $29 \mathrm{~mm}$ & $27(33.8)$ & $20(50.0)$ & $7(17.5)$ & \\
\hline $31 \mathrm{~mm}$ & $8(10.0)$ & $2(5.0)$ & $6(15.0)$ & \\
\hline \multicolumn{5}{|l|}{ Access route, $n(\%)$} \\
\hline Femoral & $61(76.2)$ & $32(80.0)$ & $29(72.5)$ & \\
\hline Subclavian & $15(18.8)$ & $8(20.0)$ & $7(17.5)$ & 0.19 \\
\hline Transapical & $4(5.0)$ & $0(0.0)$ & $4(10.0)$ & \\
\hline Moderate to severe AR after TAVI, n(\%) & $8(20)$ & $3(7.5)$ & $5(12.5)$ & 0.51 \\
\hline Pre-dilatation, n(\%) & $35(28)$ & $20(8)$ & $50(20)$ & 0.005 \\
\hline Post-dilatation, n(\%) & $10(8)$ & $12.5(5)$ & $7.5(3)$ & 0.071 \\
\hline
\end{tabular}




\begin{tabular}{|c|c|c|c|c|c|c|c|}
\hline & \multirow[b]{2}{*}{ TOTAL } & \multirow{2}{*}{$\begin{array}{l}\text { LBBB } \\
(n=40)\end{array}$} & \multirow{2}{*}{$\begin{array}{c}\text { Non-LBBB } \\
(n=40)\end{array}$} & \multirow[b]{2}{*}{ p value } & \multicolumn{3}{|c|}{ At 6 months } \\
\hline & & & & & $\begin{array}{c}\text { No LBBB } \\
(n=17)\end{array}$ & $\begin{array}{l}\text { Persistent LBBB } \\
\quad(n=23)\end{array}$ & p value \\
\hline \multicolumn{8}{|l|}{ LVEF prior to the procedure } \\
\hline Mean \pm SD & $60.0 \pm 11.8$ & $60.9 \pm 11.6$ & $59.1 \pm 12.14$ & 0.50 & $59.9 \pm 9.4$ & $61.6 \pm 13.1$ & 0.63 \\
\hline$<50 \%, \mathrm{n}(\%)$ & $14(17.5)$ & $7(17.5)$ & $7(17.5)$ & 1.00 & $3(17.7)$ & $4(17.4)$ & 0.99 \\
\hline \multicolumn{8}{|l|}{ LVEF after to the procedure } \\
\hline Mean \pm SD & $59.3 \pm 11.0$ & $56.7 \pm 12.9$ & $62.0 \pm 8.1$ & 0.03 & $59.3 \pm 10.9$ & $54.7 \pm 14.1$ & 0.25 \\
\hline$<50 \%, \mathrm{n}(\%)$ & $10(12.5)$ & $8(20.0)$ & $2(5.0)$ & 0.04 & $3(17.7)$ & $5(21.7)$ & 1.00 \\
\hline $\begin{array}{l}\text { Post-procedure TTE delay, } \\
\text { months, mean } \pm \text { SD }\end{array}$ & $8.2 \pm 4.8$ & $8.1 \pm 4.1$ & $8.3 \pm 5.5$ & 0.91 & $8.7 \pm 4.1$ & $7.7 \pm 4.1$ & 0.22 \\
\hline \multicolumn{8}{|l|}{ Absolute LVEF change } \\
\hline All patients & $-2[-8 ; 6.5]$ & $-5[-12.5 ; 2.5]$ & $1.5[-6.5 ; 9.5]$ & 0.007 & $-2[-7 ; 6]$ & $-7[-13 ; 2]$ & 0.16 \\
\hline Initial LVEF < $50 \%$ & $5.5[-2 ; 21]$ & $-2[-8 ; 2]$ & $20[9 ; 22]$ & 0.02 & $0[-2 ; 25]$ & $-5.5[-10.5 ;-0.5]$ & 0.16 \\
\hline Initial LVEF > $50 \%$ & $-3[-11 ; 5]$ & $-6[-13 ; 3]$ & $-2[-7 ; 7]$ & 0.05 & $-3.5[-12 ; 6]$ & $-7[-15 ; 3]$ & 0.32 \\
\hline
\end{tabular}

